Darko Marinković

\title{
Lifelong learning, new technologies and changes in the structure of the employed labour force
}

\begin{abstract}
One of the key characteristics of the contemporary age is the development of new technologies, production programmes and, connected with these, changes in the social structure of employees and of society as a whole. Today, we have a high level of consensus between researchers, experts and politicians that human resources is the strongest force in technological and economic development. The increasing importance of education is visible and it confirms that there is a direct relationship between the level of development and the level of investment in education. However, the development of human resources is not possible without positive social circumstances and this is particularly important for countries in transition. Social circumstances, new technologies and the process of education have to be parts of a strategy for development across the whole of society; they function within it on the principle of connected vessels. It is a precondition that the concept and practice of 'lifelong learning' must be established. Serbia has a lower level of technology and one of the main obstacles to its faster development is the lower level of education and the discrepancy between the structure of the labour force and the needs of new technologies. The long-term solution is to define and realise a new strategy which will include the democratisation and development of the education system as a flexible, open system based on ethical principles.
\end{abstract}

Keywords: new technologies, education, lifelong learning, ethics, human resources, human capital, knowledge, transition.

\section{Introduction}

The modern age has brought a whole series of changes in social relations, the creative process for material and spiritual goods and the content and manner of human life. This assertion has already come to take up a general, indisputable place in academic and professional works, political programmes and speeches; in fact, in all forms of public communication. It is by itself correct - but it is also insufficient. We are talking here about that which contemporaries have called, in each period in human history, the 'new age', arguing that it has brought justified changes in their lives and in social relations overall. From that point, it is necessary, beginning with such a general assertion, to make a further step, i.e. to analyse the social processes and relationships that mark the time in which we are living and to recognise and separate that diferentia specifica by which the modern age can be separated from previous epochs 
in human history, i.e. the concept which represents the driving force behind all social processes and changes.

Within the search for an answer to this question, one fact has crucial significance. In a time that may be characterised by diversity, we can see the points of a greater and greater complexity of the social structure, the richness of different forms of social life, ongoing confrontation and, frequently, conflicts in the different visions and conceptions of political, economic and social society organisations between which a high level of consensus otherwise exists. Politicians, economists, sociologists and scientists in related areas, who have different theoretical, political and ideological orientations, are agreed that human resources are the key driving force in the economic and technological development which drives the quality of human existence. With this in mind, we are not, of course, questioning the significance of new technologies but we do have to remember that they are the result and conception of human creativity, skills and knowledge. ${ }^{1}$

Envisaged within the dimension of time, from the first industrial revolution until today, it can be identified that human knowledge and new technologies have been connected by the principle of conjoined circumstances. It is historical that the first, significant steps in technological development, by which we mean the dynamic, creative force essential to human work, started when the human mind and spirit were liberated from their dominant, centuries-long bonds of a narrow approach to nature, social reality and the very universe itself.

Ultimately, new technologies can be defined as externalised human knowledge. This means that new technologies are not simply just the machines and the apparatus, but their specific characteristic is that they are the manifestation of the creative power of human work, life vision, courage and the readiness of human beings to demolish the obstacles that limit them. ${ }^{2}$

In other words, technologies and knowledge represent two phenomena which are, essentially, one and the same thing. This assertion confirms the experience of all of today's economic and technologically advanced societies. Namely, it is instantly recognisable that economic growth and technology have encouraged the development of societies whose population is highly educated and where a significant part of the means and efforts of the relevant social factors are invested in the development of the education system. Speaking in terms of the language of mathematics, it can be said that there exists a direct relationship between, on the one hand, the degree of investment in the education system and the level of education of the citizens of one nation and, on the other, the degree of its economic and technological development.

It is correct that the permanent installation of new technologies that, initially, were more and more machine-based, then automated and, today, computerised, have provided for the better incorporation of unskilled and semi-skilled labour in the labour process. We are talking here about new technologies which provided for workers who did not have a more advanced level of education to be trained, and relatively

1 John Bratton and Jeff Gold (2007) Human resource management: Theory and practice Palgrave Macmillan: New York.

2 Keith Grint (2003) The sociology of work Polity Press: Cambridge, UK. 
quickly, to carry out a certain number of simple operations on a machine, i.e. within the work process. A superficial observation of this process, on a single plane, can appear as an optical illusion and may lead to some incorrect conclusions being drawn. If we determine what we see at first sight, it can be said that such a process may lead to a continuing degradation in the structure of skilled and educated labour. We have regard here, however, for a further trend in the development of new technologies and the programmes and products which are based upon them. Namely, new technologies objectively demand a higher degree of general education, proficiency and expert skills and knowledge so that they can be effectively managed.

This factor is present in the economic life of society in a very practical manner, through the profitability and rivalry of companies in a competitive international market. Namely, to survive in the market, the capital owners (i.e. managers) have had to invest at one and the same time in new technologies and in the development of human resources. Throughout the whole period of capitalist trade, the development of the market in this direction could be characterised as the tendency to seek out the continual growth of resources for the development of human capital - or, as we may say as economists, the structure of capital has been changing in favour of that part which is invested in human resources. There is a strong relationship between centrifugal and centripetal forces - knowledge has created new technologies while those new technologies have required, and then encouraged, an increase in the existing degree of knowledge. ${ }^{3}$

New technologies, new means of production, new products and the changed economic structure of society have conditioned changes in the social structure and in the content and manner of everyday life.

In parallel to this streams the process of creativity regarding new products fit for new human needs. New technologies, i.e. the growing dynamics of their development, continually require a wider circle of educated people with new professional skills and knowledge. At the same time, the process of education is becoming longer and longer while the need for the ever-expanding acquisition of new knowledge, i.e. the advance of professional skills and knowledge, becomes more significant and present more completely in all activities. The period in which machines become obsolete has also been shortening. All the while, we are growing more conscious of human freedoms and rights.

The decisive step, and a source of permanent energy for the wider dynamic of the development of the economy and of technology, is indicated by the democratisation of education - that is, the abandonment of the system in which education was the privilege of the entrepreneurial minority. In that manner was the position of the ruling class maintained but, at the same time, it presented an obstacle to economic and technological progress. Today, education provided without gaps and on a free of charge basis represents an incontrovertible, generally accepted right of civilisation. Furthermore, many developed countries have undertaken a whole series of measures to make intermediate and higher education accessible to a wider circle of people, as

3 Raymond Miles (1965) 'Human relations or human resources?' Harvard Business Review 43(4), July-August: 148-163. 
much for developing a consciousness about education as a basis for social development as for establishing a reliable path for social promotion. This extended coverage of the population by the education system was one of the basic generators of a new social structure and, above all, of a social middle class that, today, represents one of the bases of the economy and social stability in economically developed countries of Europe and the world. ${ }^{4}$

The process of a greater compulsion toward the acquisition of knowledge and the enlargement of the circle of those belonging to the systematic education process has brought us to the stage of defining a new idea - that of intellectual capital. Of course, we are not just talking about a new theoretical or practical idea but about a new social reality in which intellectual capital has become one of the key subjects of business and trade, as well as a basis for confrontation and division. New technologies without knowledge - not only could they not be developed, neither could they be lasting, or even used in the first place. It follows that the commercialisation of knowledge, or so-called 'know-how', is one of the most frequent subjects of business transactions. In that way, society has definitely entered a phase in which science and knowledge represents a direct force in development and production. This process has been developing more and more on a global plane. That there are differences in the scale of scientific development and knowledge in some countries and regions of the world does not bring into early question such a statement.

Nevertheless, it does demonstrate that we are talking about the struggle for social power and a dominant position in the economic and political life of the world which is being increasingly transferred to the field of knowledge and science. ${ }^{5}$

\section{Social surroundings, new technologies, lifelong learning}

In the last few centuries, education has changed the picture of the world, has freed people from many fears and prejudices and has opened the space for the enrichment of the content of human life. It has represented one of the basic driving forces behind social progress. The process of the democratisation of the education system and its greater openness toward all social classes was also the basic generator of changes in the social structure for members of the working class and also for wider society. In the whole history of domestic civil confrontation, education has had a function as a centrifugal force behind vertical social mobility. However, in no society, including the most democratic ones, has education functioned as an autonomous system, but has always been a part of wider social processes. From that comes the need for education to be seen as a coherent part of the broader social environment, possessing an interdependence with the other aspects and contents of that social environment.

Education in all societies, as well as in modern global society, has inspired numerous changes. From the other side, social movements have accomplished a significant influence on the education process which has moved in two directions at once both encouraging and limiting. Gradually, and in one long-term, complex process, ci-

4 Anthony Gidens (2003) Sociology Faculty of Economic Sciences, Belgrade.

5 Francis Fukujama (1999) Social capital and civil society paper prepared for delivery at the IMF Conference on Second Generation Reforms, 1 October. 
vil society has opened up and democratised the process of education. It is important to bear in mind in this moment that the crucial point of this process is represented by the critical mass of industrial production, scientific and technological advance requiring the increasing engagement of a greatly expanded potential of creative human beings.

Even so, the democratisation of education, initially underpinning the greater real accessibility of education to the largest social groups, has been conditioned by the overall changes to the political and economic organisation of society and to real social relations. In another words, and this is confirmed by the practice of modern, economically developed, democratic societies, the democratisation of education has been possible only in an appropriate global environment. The citation of particular elements within the social environment is necessary since, by using comparative methods, we can in this way compare the state of countries in transition, including Serbia, so as to gain a complete and objective insight into the advantages of, and limitations to, the democratisation of education in these countries. Therefore, of course, it has also to be borne in mind that the democratisation of education, in terms of its adjustment to the new social circumstances, is itself also a component of transition. ${ }^{6}$

In any analysis of the relationship between the social environment and education, the democratisation of education could be treated as one aspect of confrontation with a reality that imposes the need for the democratisation of education but which may lack the real social conditions for this to be done. In other words, before embarking on a process of education democratisation, it is necessary that the ruling elite has both the will and the responsibility. It considers that the ruling elite must see its interests in democratising education. At the same time, it is necessary to have an appropriate level of consciousness of the need for, and significance of, education as the basis for quality of life, freedom and advancement in the social hierarchy. The democratisation of education, with all the gains which it brings, is possible only where the majority of citizens believes in the force and sense of education as providing the drive behind development and personal social promotion. Of course, it has implications for the whole social system, which has to be fair, democratic and based on the principle of equal opportunity in which knowledge wins. Vice versa, in societies based on principles of gender, autocracy and nepotism, in which the social position of the individual is built on the basis of political affiliation, loyalty and obedience, education loses a great measure of its basic sense and compulsive force as the democratisation of education is converted into a void story. In other words, education in the new social circumstances can be seen not only as an organised system of knowledge transfer but also as a part of value systems and moral principles.

At the same time, the mutual connection and conventionality of education and the social environment warns us that education can not be democratised and be developed overall as an isolated system - that is, education can not be democratised in the absence of the democratisation of wider society. The opening of the education process toward all classes of society, regardless of gender, religion, nation, political de-

6 Enrico Colombatto (2001) 'On the concept of transition' Journal of Markets and Morality 4(2): 269-288. 
dication, social origin, etc. is, as a matter of fact, one of the most significant and most important social fronts in the battle against discrimination or in the recovery of the principles of equal opportunity.

Today, history and modern practice in economically and technologically developed, democratic societies confirms for, and warns, countries in transition and their strategists that it is not possible to remove discrimination from the process of education but not at the same time removing it from political life, position, advance and the right of access to social and health protection, or indeed the whole complex of human, political, economic and social rights. On the contrary, these processes fly in parallel, stimulating and relying on one another where education has a specific role as a source of energy for all the other processes. ${ }^{7}$

Only in that manner has it been possible to change the relationship of wider society, and primarily its ruling elite, toward education. It is considered appropriate that the constitutional and legal regulation of this area, and the growing amounts set aside for it from central budgets, is based on an open system of education, accessible to the members of all classes. Of course, it always depends on society's real material power. In that way lies the parallel accomplishment of these two targets - a system of education which corresponds to the growing requirements of new technologies itself and, on the other side, the installation of the principles of social justice and solidarity in that system. An analysis of this interdependent relationship directs us to the conclusion that a more dynamic development of new technologies, with its demand for a suitable, more educated labour force structure, has influenced the degree of compulsion behind the democratisation and opening up of the education process while also influencing the democratisation of wider society. That kind of conclusion confirms that there exists in the modern age a direct relationship between the level of development and production within society and human freedoms and democracy. U1timately, it does not to be specially proved that the democratisation and openness of the education process is not possible in those societies where the right to life, the right to work and the right to decent earnings, and freedom of choice of profession and freedom of movement, are not also established and properly protected. In other words, education as the driving force of economic and wider social development can accomplish its full sense only when people have alternatives.

The increasingly dynamic development of new technologies and the growth of the productive, creative power of human work personified in a larger amount of material goods and the evolution of new human needs has, besides everything else, brought us to the point where the formal education system is not able to respond with the necessary dynamic power to the growing demands of technological development. The process of study has gradually and increasingly moved into a situation in which the process of work has become its ingredient. In that way, a new social process has been established, as a part of the labour process and of technological development that of lifelong learning, or the continuing improvement of the professional and expert skills and knowledge of each employed person. The idea of lifelong learning com-

7 Miro Prokopijević (2001) Transition Working Paper 15/01, International Centre for Economic Research: Turin. 
prehends in this sense a process of formal education - starting from elementary school up to the highest levels of academic education - as a permanent process of the acquisition of practical experiences, the confrontation of new social circumstances in the company and society as a whole, the following of specific scientific and expert development of individual disciplines and the ongoing improvement of professional and expert skills and knowledge. The process of lifelong learning is based on the openness of wider society, local communities, companies and each individual toward change and a readiness to accept professional challenges which bring new technologies and new production programmes, including ones that change fundamentally the content and manner of our lives. When we bear all of that in mind, it is clear that the process of lifelong learning has a key foothold in the formal system of education, or at least in its practical results.

\section{Lifelong learning, changes in the structure of employment in Serbia and the confrontation of a spell-bound circle of poverty}

All countries in transition, including Serbia among them, have been confronted with, beside others, numerous contradictions, limitations and new requirements in the area of education and the adjustment of the structure of the labour force to the new social circumstances, i.e. the new demands of national economies.

It can be said quite openly that the restructuring of the labour market is socially the most risky, the most conflictual and the most expensive part of the restructuring processes of the economies of countries in transition. ${ }^{8}$ Of course, the need to engender the concept and practice of lifelong learning also had an essential influence on this process. In this direction, as in other segments of the transition, a particularly powerful element was the inheritance of the previous period, which had both positive and negative sides. This legacy had two key aspects. The first was related to education in the previous system being open and accessible to the members of all social orders which, therefore, constituted the biggest and most propulsive channel for social mobility and dynamic change in the social structure. The other aspect is related to the growing variance between the content of the education system and the demands of the economy, which was ultimately brought to the point where schools and faculties were predominantly geared towards producing personnel for the labour market. It was, in other words, an unfavourable starting point for entry into the otherwise complex, conflictual and socially expensive transitional demands made as regards the plan for the restructuring of the labour market.

Primarily, it is necessary to recognise the educational structure of the population and of those in employment since this represents the starting point for economic and technological development and the appropriate content and dynamics of lifelong learning. In that regard, and from the first stage, we must bear in mind one major limiting factor - that Serbia is still, and considerably more so than economically developed countries in Europe and the rest of the world, confronted with the issue of illiteracy. This part of the population is practically excluded from the processes of

8 Employment and Labour Policy in South-Eastern Europe Friedrich Ebert Stiftung Regional Office: Belgrade, 2002. 
economic and technological changes and developments. According to the 2002 data of the Statistical Office of the Republic of Serbia, 3.4\% of the total population are illiterate, of which three-quarters are women. ${ }^{9}$

Fortunately, positive movement can be observed considering that the same data source in 1991 quoted the percentage of illiterate people as standing at $6.3 \%$. However, it is necessary to bear in mind that the situation is, in practice, significantly worse than indicated by the data. The data refers to a total number of illiterate people of 415220 (the equivalent of two towns the size of Kragujevac) but experts believe that the proportion of those who are 'functionally illiterate', i.e. with incomplete elementary schooling and thus without a basic knowledge of professional and expert skills, which today represents a very necessary component of general and expert education, is considerably greater. The data in the following table indicates the full picture:

Table 1 - Educational background of the population older than 15 years

\begin{tabular}{|l|c|c|c|c|}
\hline Republic of Serbia & Total & Employed & Unemployed & $\begin{array}{c}\text { Non-active } \\
\text { population }\end{array}$ \\
\hline Total & 6512299 & 2630691 & 693024 & 3188584 \\
\hline Without schooling & 263510 & 30866 & 4601 & 228043 \\
\hline Incomplete elementary school & 783014 & 176899 & 14879 & 591236 \\
\hline Elementary school & 1554618 & 456539 & 131859 & 966220 \\
\hline High school & 3136788 & 1506376 & 480920 & 1149492 \\
\hline Academy & 337021 & 180026 & 31974 & 125021 \\
\hline Faculty, academy or college & 437376 & 279985 & 28820 & 128571 \\
\hline
\end{tabular}

Source: RZS [Statistical Office of the Republic of Serbia], Belgrade, 2006.

From the data included in Table 1, it is clear that the structure of the population contains a high percentage of people who have, at most, only elementary education while, for some of these, even this is incomplete. Some $40 \%$ of the total of the population aged over 15 have an educational background which is elementary (or have no schooling at all). That data speaks enough by itself, while it is evident that this represents a significant restriction on the structure of the labour market. The dominant educational group in the population is taken by people with secondary schooling, who make up $48 \%$ of the total population. Finally, those with faculty education make up $7 \%$ of the total population, a number which is considerably lower than the equivalent figure for developed countries in Europe and the rest of the world. The level of education is also in this case an indicator of the state of relations with relevant social forces, above all those responsible for designing a progressive and roundly-developed policy on this question, as well as of the material power of society and its readiness for investment in raising the level of education (and its capability to do so).

9 Statistical Annual RS RZS: Belgrade, 2006. 
In this regard, Vladimir Marinković reports as follows:

There is no country today that, at least at the formal level, and to a greater or lesser extent in terms of measures and real plans, does not accept education as a significant part of the strategy for the development of society. The level of the economy and the total development of some societies, and the standard and quality of lives of the people in them, besides other relevant criteria, is measured by the percentage of national earnings which is set aside for education. A country becoming richer and richer, and more developed in its economy and technology, sees the quality of life of its citizens becoming better and it sets aside a higher percentage of national earnings for education. ${ }^{10}$

The following data on the percentage of gross social product set aside for education speaks in favour of such a view: ${ }^{11}$

\begin{tabular}{|l|c|}
\hline Country & $\mathbf{\%}$ \\
\hline Germany & $6.4 \%$ \\
\hline France & $6.4 \%$ \\
\hline Japan & $5.4 \%$ \\
\hline Sweden & $7.1 \%$ \\
\hline USA & $6.4 \%$ \\
\hline
\end{tabular}

It is important to emphasise that the percentages set aside for education describe a continuing growth trend, confirming that education is indisputably and increasingly becoming a direct force for development and productivity. In that manner is the circle of education and technological and economic advance successfully closed. A higher level of education transforms into a dynamic economy and technological advance, which provides that a higher part of national earnings may be set aside for education and academic research work. However, in transition countries, Serbia included, these processes, confronted by numerous limiting factors, often proceed in the opposite direction. Education and its democratisation and adjustment to the new social circumstances have been slowed down and often totally blocked by poverty as an objective material factor, as well as by psychology or the poverty syndrome.

Education must also confront the phenomenon in which poor nations, where Serbia also, unfortunately, belongs, have a different psychology and manner of thinking than nations who are rich and developed. An objectively material obstacle is manifested through social product or national earnings being insufficient even for the needs and requirements of everyday life. It also limits investment in development. However, that objectively limiting material factor always goes with the psychological one, which can be even more resistant and dangerous than the material one.

10 Vladimir Marinković (2008) Management of human resources and strategy of development in the process of globalisation monograph, MVSSP: Belgrade.

11 EUROSTAT (2006). 
The limitations imposed by the lack of material resources restricts the volume of investment in development functions, including in the development of education, and it has an unfavourable influence on economic and technological development. In that manner, Serbia is paying, in the long-term, the price of its economic and technological backwardness; that is, it has become a part of a spell-bound circle based on its own poverty. The level of poverty overall in a society conditions the level of poverty in its investment in education and science; this generates further poverty in all areas of social life; and so it goes. ${ }^{12}$ It resembles life and the logic of life in a poor family. All it earns, and it earns very little, is spent on basic daily needs. For long-term planning and investment, nothing is left. Other than that, the present state is not the most dangerous to be in, unless people do not believe that it is iniquitous, with a sense of inevitable destiny, or that it does not offer them a viable way of life. In the meantime, developed economies, thanks to an education and population structure which is developed, adaptable to new circumstances and creative, continue on their dynamic economic and technologically progressive paths, and can thus make new and bigger investments in education and science. Thus is created a gap between rich and poor in the long-term which stabilises and becomes larger and larger.

Those who are on the receiving end of all of these processes are living - in the Serbian phrase - only to build public kitchens. Of course, all this would not make much sense ahead of time and in a situation where there is an emphasis on the responsibility of the ruling elite for the production and maintenance of the psychology of poverty.

Namely, all governments from the beginning of the nineties - that is, from the beginning of the transition - have, to a greater or lesser extent, used that dangerous and ruinous political weapon - the fear of losing one's job. And those who live everyday in fear of losing their job, those who fearfully await the following day, do not represent qualitative and grateful human material for lifelong learning and the permanent, systematic improvement of their own expert and professional skills and knowledge.

In place of the flywheel, or centrifugal force required for exiting such a state, this spell-bound circle of poverty possesses lead for legs. This makes an already difficult situation even more difficult.

The Sisyphean rock which Serbia must push uphill is the purely unfavourable educational picture of the society we are living in and the inadequate qualifications structure of an employed labour force that is obviously not in a suitable state to accept the challenges of new technologies and new production programmes, or the new approach to economic life and the market game which is its key driving characteristic.

One of the biggest obstacles is located, as usual, where we least expect it to be: in human heads, in our value system and in our way of thinking inherited from the previous period, as well as in our understanding of so-called 'absolute job security'. The latter is simply not possible in the commercial trading game, that is, the game between human capabilities and knowledge. The other element in this situation is the non-

12 Danilo Suković (2002) Poverty restrains changes and Social picture and reforms of Serbia Friedrich Ebert Stiftung Regional Office: Belgrade. 
existence of a strategy for, and practice of, a continuing, systematic qualification in entrepreneurship and in starting-up and leading self-contained economic activities, as well as in adjusting to the circumstances in which future economic life will be led.

The objectively limited material circumstances are represented by the total social price being otherwise expensive and, in the difficult transition which Serbia has experienced, this being implemented on the back of the employed labour force. Besides everything else, this has brought into creation a Latin American social structure for our society in which $7-10 \%$ are extremely rich and the other $90 \%$ more or less poor. Furthermore, living in total penury for the whole, long-term existence of the economic and social crisis, which still exists on many levels, has been the working class. The dominant groups here are made up of those who have been marginalised or totally excluded from the labour market by one or other of the following processes forced leave, technological and economic surplus, or formal or factual unemployment. Living in such humiliating conditions of social and economic insecurity, worrying and fearing for their everyday survival, they have not been able to become a creative, driving force for the economy and of technological improvement. On the contrary, they were the first and the biggest victims or, more precisely for our theme, they did not even have the opportunity of inclusion in the process of lifelong learning. In the economic vocabulary, in the process of lifelong learning and continuing professional development, and in the change and adaptation of the structure of the labour force to new technology and the development of production programmes, people have, from the very beginning, lived the life of a 'loose substance'.

\section{Instead of a conclusion - searching for exit roads from the spell-bound circle}

The interdependence of the development of new technologies, education and lifelong learning, confirmed in the strategies of development and practice in economically and technologically developed countries of the modern age, must be understood in Serbia too in only one way - as a warning that Serbia's exit from economic and technological anachronism, which has a foundation in the development and democratisation of education as an open and developed system, is possible only as one component in a development strategy for the system as a whole. ${ }^{13}$ In particular, it is necessary to establish a permanent bridge, or the principle of connected vessels, between the development strategy and the system of education, including the concept and practice of lifelong learning. In this way, changes in the social environment, in the processes driving the education system and in lifelong learning may mutually encourage each other. There is a potential source of energy in the rapid changing of the educational and social structure of the population and, above all, in the labour world and in its adaptation to the requirements of new technologies and to the changed way of life which is related to the new social circumstances.

Within that process, there must be parallel changes in all aspects of the social environment and chiefly in establishing the rule of law - that is, the equality of all befo-

13 Lj. Madžar (2004) 'Culture as factor and development limitation' in Culture and development a collection of the Institute of Social Sciences, IDN: Belgrade. 
re the law; the building and re-statement of the role and responsibilities of the institutions; and the strengthening and adjustment of the roles of the country in education and culture. We are not talking here, of course, about mechanically establishing and spreading the net of the cultural and educational institutions, but about establishing that type of concept of education and culture which will, in the most suitable way, generate and develop social capital. ${ }^{14}$

In this way, social capital can be defined as the concentrated spiritual and creative force of a nation which will, beside others, be materialised through social advance and the quality and dignity of all human life. The old Roman catchphrase 'give people both bread and games' should today be re-stated as 'give people bread, culture and education'; in other words, a nation that wants to go by the road of improvement is in need of having, at one and the same time, bread, culture and education. In the modern age, it is not possible to have movement in some imaginary way toward a situation in which citizens must be given bread in the first phase, and then, in later phases, education and culture since that bread is so small that there could be very little education and culture.

For that reason, the theory that is often present in our policy and documents of 'postponed development' is unacceptable. The mutual denominator of all these theories and policies is the postponement of developmental projects, and of development strategy in total, 'until better times', or 'when circumstances change', or 'when the suitable conditions and preconditions have been created', etc. Essentially, this means the maintenance of the existing condition, no matter whether this stems from the interests of the privileged order or else from ignorance. From that it is apparent that exiting the spell-bound circle of poverty, which is continually renewing itself, represents a radical rupture with existing practice. Underneath this lies radical confrontation, with all the limited aspects of the unfavourable and limiting social environment, as well as a concentration of all the available material and spiritual forces toward clearly-defined strategic aims.

Possessed of an immeasurable and irreplaceable role in the process of the development of education, lifelong learning, as an element in the honourable and equal game of human capabilities and knowledge, as well as in the change of the structure of employment in the function of technological development and social advance, has a moral. Better put, without a moral basis these processes lose their human and social sense and can not lead toward the accomplishment of the desired for and anticipated social aims. In this regard, Ljubomir Madžar says as follows:

The importance of the moral in practice can not be estimated. Besides the obvious value in noneconomic terms (support for patterns of behaviour that strengthen the affirmation of humanity), the moral has a clear economic significance. It directs human efforts towards productive activities and creative endeavours, and represses master-slave relations, recourse to compulsion and deception, and all other forms of redistributive behaviours. It inspires and incites ef-

14 D. Šuković (2004) 'Culture and social capital' in Culture and development a collection of the Institute of Social Sciences, IDN: Belgrade. 
forts targeted at the strengthening of the material base of society and the achievement of the highest goals in the generation of new knowledge. ${ }^{15}$

In particular here we must underline the following moral aspects. Firstly, education is, by itself, deeply ethical since, speaking objectively, an integral understanding of the world, nature and society is not possible if this is not founded on moral principles.

Secondly, education, including lifelong learning as a component in this process, is based on a developed consciousness and the motivation of all actors; above all, those who, in different life phases and professional careers include themselves in the process of lifelong learning. And the motivation for study, i.e. the continuing improvement of professional skills and knowledge, is based on the ethical principles established in society as well as on the moral strength of each individual.

\section{References}

Bratton, J. and J. Gold (2007) Human resource management: Theory and practice Palgrave Macmillan: New York.

Colombatto, E (2001) 'On the concept of transition' Journal of Markets and Morality 4(2): 269-288.

Employment and Labour Market Policy in South-Eastern Europe collection by the Friedrich Ebert Stiftung Regional Office, Belgrade, 2002.

EUROSTAT, 2006.

Fukujama, F (1999) Social capital and civil society paper prepared for delivery at the IMF Conference on Second Generation Reforms, 1 October: IMF.

Gidens, A (2003) Sociology Faculty of Economic Sciences, Belgrade.

Grint, K (2003) The Sociology of Work Polity Press: Cambridge, UK.

Madžar, $\mathrm{Lj}$ (2004) 'Culture as factor and limitation of development' in Culture and development a collection of the Institute of Social Sciences, IDN: Belgrade.

Marinković, V (2008) Management of human resources and strategy of development in process of globalization monograph, MVSSP: Belgrade.

Miles, R 'Human relations or human resources?' Harvard Business Review 43, JulyAugust: 148-163.

Prokopijević, M (2001) Transition Working Paper 15/01, International Centre for Economic Research: Turin.

Šuković, D (2002) Poverty stops the reforms and Social picture and reforms of Serbia research studies, Friedrich Ebert Stiftung Regional Office: Belgrade.

Šuković, D (2004) 'Culture and social capital' in Culture and development a collection of the Institute of Social Sciences, IDN: Belgrade.

15 Lj. Madžar (2004), op. cit. 